\title{
Interpretive Play and the Player Psychology of Optimal Arousal Regulation
}

\author{
Matthew Higgins ${ }^{1[0000-0002-1970-3780]}$ and Peter Howell2[0000-0002-4673-6422] \\ University of Portsmouth, Portsmouth UK \\ ${ }^{1}$ Matthew.Higgins@port.ac.uk \\ ${ }^{2}$ Peter. Howelleport.ac.uk
}

\begin{abstract}
Building on previous discussions of interpretive play in story-focused digital games, a psychological foundation of narrative interpretation is proposed. First, how narrative information is synthesized with prior experiences and expectations into 'situation models' in long-term memory. Second, how pleasure is derived from increased arousal through engaging with novel, unfamiliar stimuli. This psychological foundation is then compared to contemporary approaches to narrative design, particularly in Her Story and Dear Esther. The relevance of the proposed cognitive psychological foundation is also considered in regard to digital games with no documented intentional use psychologically, primarily through an analysis of player behaviour and response in Gone Home. Results are comparable to the psychological model, particularly the prominent roles of recalling and forming expectations, and how player attention is often attracted to novel, unfamiliar, or unexpected stimuli. The ongoing aim of this work is to further investigate interpretive play in the context of digital games and continue to develop the cognitive psychological foundation. Future work shall also contextualise the research and findings though the development of commercial games.
\end{abstract}

Keywords: interpretive play, arousal regulation, digital games, narrative, cognitive psychology, schema.

\section{Introduction}

The concept of interpretive play has been discussed previously in the context of digital games, with various perspectives on how the interpretation of a narrative specifically can be considered a form of play. Upton [1] argues that whilst story games possess a "vacuity of their moment-to-moment play", this is overshadowed by a "compensatory complexity" in the "interpretive play" spaces that they construct, broadly suggesting that the interpretation of narrative can be considered a form of play in itself. More recently, Bozdog and Galloway [2] adopt this perspective in an analysis of how What Remains of Edith Finch [3] supports interpretive play through slowness, ambiguity, narrative, and aesthetic aspirations.

Previous work has explored psychological foundations of interpretive play. For example, Boyd [4] pays particular attention to the evolutionary purpose of play as a form 
of practice and training and argues that engagement with art more broadly is a form of cognitive play.

Further exploration of the psychology of interpretive play is warranted. A detailed psychological foundation will aid in discerning methods via which game designers can facilitate interpretation as a form of play in their games to enhance the player experience. This paper suggests that the cognitive processing of narrative stimuli may be considered a playful activity, particularly when sought out as a source of increased arousal and enjoyment. Two key psychological aspects are considered: first, the processing of narrative stimuli into mental models in long-term memory; second, the cognitive process through which pleasure is gained by reaching and maintaining an optimal state of arousal. A theoretical model of optimal arousal regulation in interpretive play is presented and applied to a discussion of contemporary approaches to storytelling in digital games, specifically in Dear Esther [5] and Her Story [6]. This discussion is then further contextualized in a thematic analysis of a stimulated recall study of players of Gone Home [7]. This analysis further demonstrates the applicability of the theoretical model in a digital game without the explicit psychologically inspired design intent that both Dear Esther's and Her Story's creators describe.

\section{The Cognitive Psychology of Narrative Interpretation}

Cognitive processing can be more broadly understood as the coordination and management of stimuli through working memory [8] which interfaces with long-term memory to organize and store information for subsequent retrieval. How stimuli are organized and stored in long-term memory and recalled by working memory is of particular relevance to narrative processing.

Schema theory proposes that long-term memory is an associative structure of clusters of familiar and relevant memories and knowledge specific to particular phenomena $[9,10]$. This associative structure affords quicker processing of relevant concepts and the formation of expectations of potentially relevant stimuli.

Psychological studies of narrative demonstrate the use of schema when participants interpret and retell a narrative [11-13], with individual interpretations varying due to sociocultural differences between participants. Retellings of the 'War of the Ghosts' narrative in Bartlett's study for example, found that these interpretations aligned more with the participant's individual sociocultural backgrounds, with a Native American story structure being retold through a more typically English lens. Schemas differ between individuals and are influenced by various factors, including prior experience of the stimuli or situation, and sociocultural background. When playing games, it is likely that individuals have specific schema for different media, genres, or franchises, as outlined in Howell's [14, 15] discussion of ludic cognition and methods of disrupting recall of schemas in horror games (specifically, in the development of Amnesia: A Machine for Pigs [16]). Interpreting narrative involves the similar activation in long-term memory of relevant experiences and expectations of narrative (e.g. genre, medium, or common story structures) [17] which then help in forming understanding and expectations of the current narrative via working memory. 
The understanding of a narrative, and any associated expectations, are considered to be stored in long-term memory in the form of situation models [18, 19], which can be understood in this context as narrative-dedicated schema. A situation model is a synthesis of the meaning inferred from the text (i.e. the game) and an individual's relevant schema in long-term memory. Situation models can contain a large amount of complex data, such as information regarding the speaker or narrator, character intentions, relationships, opinions, and emotions. Zwaan et al. [20] propose several categories of information that an individual's situation model may contain, described as five 'event indices': temporality, spatiality, protagonist, causality, and intentionality. Zwaan et al. argue that each of these indices are monitored and updated when any change, or discontinuity, occurs. For example, if a significant shift in time occurs, the temporality index of the situation model is replaced either with an existing, more relevant index or with a newly constructed index. Zwaan et al. suggest that effort of comprehension positively correlates with discontinuity and consequent updating of event indices.

Situation models may be updated via an incremental process, with new information being gradually implemented. Zacks et al. [21, 22] argue that if a situation changes entirely, such as between scenes in a film, or chapters in a book (which they term 'event boundaries'), then the existing model may instead be replaced by a prior model, or with a newly constructed situation model. This 'global updating' is also suggested to be involved in the prediction of future events, or if significant information is introduced that requires a large portion of a narrative, or multiple event indices, to be reconsidered for example, a narrative twist. Further research on event boundaries also suggests that situation models are more regularly updated at event boundaries [23], at the start and end of events. This also suggests that individuals switch to relevant situation models depending on the current state of a narrative. For example, the many characters and storylines in Detroit: Become Human [24] that the player experiences will involve a situation model for events occurring in Connor's storyline and another for events occurring in Kara's. The player must switch between situation models as they switch between storylines in different chapters; as storylines merge later in the game, the player must also construct new situation models through combining relevant aspects of prior models.

\section{The Pleasure of Narrative Interpretation}

Various psychological theories discuss how humans can derive pleasure from cognitively engaging activities and suggest that individuals seek out novel, unfamiliar stimuli. There is a distinction between the pleasure experienced from this form of engagement as compared to pleasure experienced as a direct physiological response. For example, Oatley's taxonomy of emotional literary response [25] suggests responses from the 'external', where the reader 'confronts' the text to discern meaning (affect from assimilation and accommodation to schema), and 'internal', where the reader 'enters the world of the text' (affect through sympathy, empathy, or emotional memories triggered by the text). Csikszentmihalyi [26] makes a similar comparison between pleasure and 'enjoyment', the pleasure derived from more effortful activity, such as playing a 
game of tennis or reading a book. Oliver and Bartsch [27] similarly propose the distinction between 'enjoyment', being the immediate affective response to media, such as humour from comedy or fear from a thriller, and 'appreciation' as the cognitive response, associated with meaningful and thought-provoking media experiences. In the current discussion, interpretation as a means of deriving pleasure from a narrative aligns principally with 'appreciation' or Csikszentmihalyi's 'enjoyment'.

Focusing on the pleasure derived from cognition, the 'need for cognition' describes a tendency to engage in and enjoy thinking, with "a need to structure relevant situations in meaningful, integrated ways" and "a need to understand and make reasonable the experiential world" [28]. Furthermore, some individuals have a greater tendency to enjoy cognitive effort. For example, in a study in which participants identified as high or low in the Need for Cognition Scale completed either a simple or complex version of a number-circling task, "subjects categorized as high in need for cognition reported enjoying the complex task more than the simple task" $[29,30]$.

Psychological perspectives on curiosity further support the assertion that individuals actively seek out novel or unfamiliar stimuli. Optimal-arousal theories of curiosity suggest that individuals desire to achieve and maintain a particular state of pleasurable arousal and will therefore engage in 'exploratory behaviours' (i.e. curiosity) and seek out new information to achieve this optimal arousal [31, 32]. Physiological arousal in this context is how wide awake, alert, or excited someone is, which determines the level of attention directed towards a stimulus. This is not directly linked to pleasure, but rather dictates to what degree we are aware and engaged. Further research also suggests that individuals engage in exploratory, curiosity-driven behaviours to reduce displeasure found in experiences of uncertainty [33,34], in which seeking and acquiring further information that reduces the uncertainty is consequently 'rewarded' with pleasure. This understanding of curiosity and resolving uncertainty is reflective of Costikyan's discussion of the necessity of uncertainty in games [35] and more specifically parallel's To et al.'s [36] elaboration of 'narrative anticipation' as 'curiosity about the complex or ambiguous' and the player's desire to fully understand a story and it's 'internal logic'. This is also similar to the concept of 'cognitive closure', which also describes a motivation to seek out information to resolve or reduce an ambiguous situation [37-39]. Theories of cognitive closure distinguish between individuals that are keen to seek out closure and resolve ambiguity, and those that seem to be more comfortable with an ambiguous situation and have no immediate desire to resolve ambiguity, suggesting a threshold between individuals' enjoyment of more or less cognitively effortful activities.

Berlyne's [40] perspective on the 'psychobiology' (i.e. the combined functionality of psychology and biology) of aesthetics more broadly considers arousal and its necessity to the experience of pleasure from engaging with aesthetic objects, such as art and media. While arousal is not directly linked to pleasure, heightened arousal can lead to both pleasure and displeasure (and in turn, aversion); the arousal allows individuals to direct attention towards a stimulus, prepares the body and mind for activity with a heightened awareness of the environment, and heightens preparedness to process more stimuli and information. 
In aesthetics, Berlyne argues that arousal is provoked by discrepancies between the content of an individual's schema and the content of, or meanings implied by, the artistic work or text being engaged [41, 42]. Arousal can be increased when properties of a stimulus are novel, surprising, complex, ambiguous, or puzzling - when existing schema cannot be used to easily understand the stimuli. Like curiosity's uncertainty or novelty, the discrepancy between schema and text results in an initial rise in arousal. This increased arousal, which can be termed arousal boost, can be pleasurable. However, higher levels of arousal can also be overwhelming and unpleasurable. For example, if a narrative is too difficult to understand then the arousal state becomes excessive and interpreting the narrative can become unpleasant. However, reducing high levels of arousal, which can be termed arousal reduction, is also pleasurable (potentially due to the removal of displeasure). Thus, the interpreter of the work derives pleasure from both forming (i.e. arousal boost) and resolving (i.e. arousal reduction) interpretations and expectations of narrative. The experience of arousal boost and arousal reduction, specifically in the pursuit of pleasure, has been further evidenced in psychological experiments that monitored physiological responses of participants while engaging with media such as literature [43, 44], television [45], film [46], and music [47].

When relevant schema are more easily determined and accessed in familiar situations and in response to familiar stimuli, a quicker, automated, 'habitual' processing occurs which Berlyne implies provokes less arousal boost. Berlyne therefore outlines various factors of 'dishabituation' that aim to discourage 'habitual processing' and cause access to relevant schemas to become more difficult, with the intent to increase arousal boost. These factors are novelty, expectations, complexity, conflict, ambiguity, and instability. Adopting Piaget's [48] perspective on assimilation and accommodation of schema, Oatley [25] also discusses how pleasure can be experienced through the easy assimilation of new information into existing schema, and the more challenging accommodation of information via substantive (re)construction of schema. Douglas \& Hargadon [17] similarly explain a difference between the enjoyment when schema are easily accessed (which they align with the pleasures of 'immersion' in a text) and when access to schema is more challenging (which they align with the pleasures of 'engagement' with a text).

Brewer $[49,50]$ adopts the concepts of arousal boost and arousal reduction when proposing additional perspectives for the manipulation of arousal. Brewer suggests that narrative consists of a 'discourse structure' that communicates the underlying story's 'event structure', in which the same event structure (i.e. the story) can be represented in multiple forms of discourse structure (i.e. the storytelling). For example, the numerous retellings of Romeo and Juliet may be considered as variable discourse structures using the same event structure. Brewer suggests variations of discourse structure that facilitate either surprise, curiosity, or suspense. In each, the same events are communicated at different times in the narrative so that expectations are influenced and/or subverted in order to instigate changes in arousal. Adopting Hitchcock's example of a bomb under a table at which two characters are conversing [51], Brewer suggests surprise would involve subverting expectations with unforeseen events or information later in a narrative (e.g. the bomb suddenly explodes and harms the characters), whereas suspense and curiosity involve providing some information earlier on in order to elicit 
uncertainty throughout a narrative (e.g. the audience is told that a bomb is under the table, unbeknownst to the two characters).

\section{A Theoretical Model of Arousal Regulation in Interpretive Play}

Bringing together the body of psychological literature discussed previously, narrative enjoyment as a function of level of arousal and proximity to optimal arousal can be summarily understood as a cycle of arousal regulation (Figure 1).

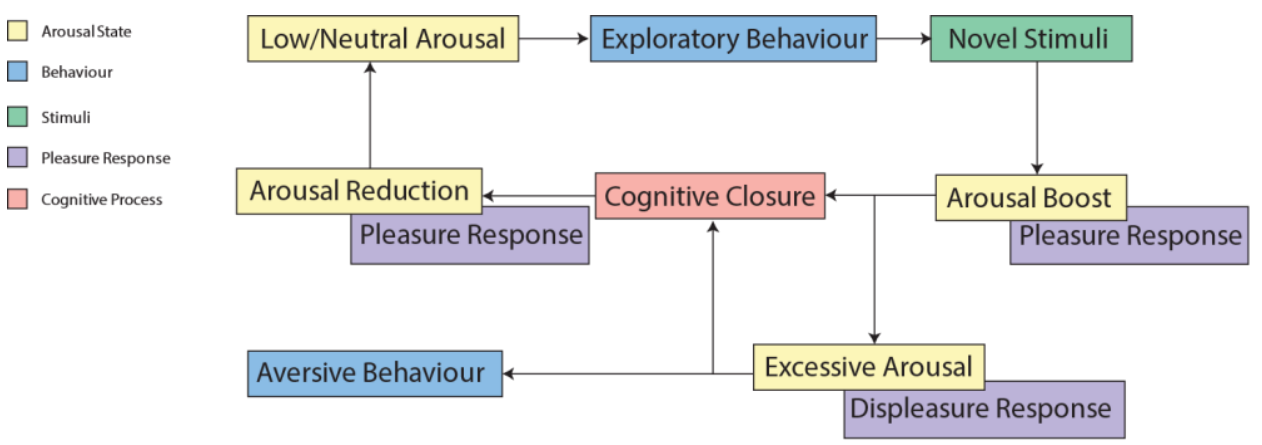

Fig. 1. Theoretical Model of Optimal Arousal Regulation in Interpretive Play

Starting with low/neutral arousal, novel stimuli trigger an initial arousal boost and consequent pleasure response. Theories of curiosity suggest that, depending on the mood of an individual, novel stimuli may be actively sought out through exploratory behaviour in pursuit of this arousal boost. Until cognitive closure is achieved, and the novel stimuli are resolved, arousal may continue to rise and fall as the player forms expectations of the narrative's uncertainty. Depending on the arousal potential of the stimuli (i.e. how unfamiliar or novel the stimulus is), this may rise to a level of excessive arousal and trigger a displeasure response, which may result in aversive behaviour (e.g. disengagement with stimuli). Regardless, once the stimuli are familiarised or resolved, arousal reduction occurs and triggers another pleasure response.

The threshold for unpleasurable arousal, and therefore the arousal-potential of stimuli, differs between individuals. As theories of curiosity and cognitive closure also suggest, individual tolerances for ambiguity differ, meaning some may be more comfortable with a certain degree of ambiguity, whereas others would be uncomfortable or dissatisfied. Either of these may result in more, or less, curiosity-seeking behaviour; individuals comfortable with ambiguity may consequently enjoy seeking our more uncertainty, but also may be less motivated to resolve uncertainty due to their comfort. Uncomfortable individuals conversely may be more motivated to resolve uncertainty and reduce their discomfort, or may disengage entirely to avoid further discomfort.

This psychological understanding of narrative interpretation, and how pleasure is derived from narrative, can firstly help understand contemporary approaches to storytelling in digital games and secondly, can also provide a psychologically grounded 
approach to design for story-focused digital games. These two aspects are examined in the following sections.

\section{$5 \quad$ Arousal Regulation in Contemporary Narrative Design}

Aspects of this psychological understanding of narrative interpretation and enjoyment via arousal regulation can be seen in contemporary practice. A broader, implicit, 'gut' understanding of audience psychology may inform the practice of many writers and game designers already, which is reflected in the psychological validity of methods that are typically employed and recommended in creative writing more widely. For example, Hemingway's iceberg theory [52], in which details and events are often omitted to strengthen story, can be argued to discourage easy accessing of schema by requiring readers to infer the missing aspects. However, there are examples of more explicitly intentional consideration of player psychology to inform the writing and design of story-focused digital games; specifically discussed here are the documented approaches to Barlow's Her Story [6] and Pinchbeck's Dear Esther [5].

Sam Barlow, writer of Her Story and Telling Lies [53], discusses "telling the story using the player's imagination" [54]. Barlow notes that audiences are increasingly "genre and story-literate", in which they are aware of "every possible combination of plot and character", suggesting that this literacy and familiarity with specific genres and story-structures is part of a player's toolkit that can be leveraged by designers. Also citing Hemingway's Iceberg theory, Barlow argues for the omission of pieces of a narrative and suggests that a story is "all about what you don't show". Moreover, Barlow argues that this method is about "leveraging the imagination" and "engaging the imagination by not showing things". Barlow suggests that depriving content of clear context encourages players to infer their own interpreted context, describing Her Story's onesided video clips and how players must infer the other, missing half of an interrogation scenario. Barlow also explains that the video clips are displayed non-sequentially, thus requiring players to further interpret how the interview clips relate to one-another chronologically. This method of non-chronological storytelling can also be found in games such as Thirty Flights of Loving [55] and Virginia [56], further suggesting a possibly unintentional application of audience psychology in games more broadly.

Barlow also discusses twists, and how they force a "reboot of the simulation" (perhaps comparable to mental/situation models), requiring the player to reconsider previously interpreted information to account for new information. Following this, Barlow also suggests a manner in which the player's "immersed state is pushed back", stating that due to the player's imagination "working so hard to believe that this is real", the player's imagination will consequently push back to reassert the player's belief of the fictitious. Barlow's suggestion is to momentarily cast doubt over the player's presence in the fictional world, thus encouraging the player to resituate themselves or "engage even harder to believe this is real". One way in which Barlow achieves this is through the reflection of the player-character on the in-game computer monitor, where an occasional strike of lightning reveals a glimpse of a young woman's face. 
Barlow's approach is comparable to the psychological foundation of narrative interpretation. The leveraging of players' established knowledge of genre and story reflects the concept of a schema in long-term memory and expectations formed from prior experience of similar phenomena. The consequent omission of details from Her Story's video clips, and the non-chronological order in which they are viewed, discourages easy access to and use of these expectations. Barlow's discussion of twists also compares to situation models and similarly suggests that introducing significant, unexpected, or discontinuous information may result in global updating (or 'rebooting the simulation').

Pinchbeck's approach to the design of Dear Esther is more explicitly evidenced as compared to Barlow's discussion of Her Story, originating with research regarding the application of cognitive psychology in understanding the effect of narrative on the experience of presence [57]. Further research also investigated story first-person shooters (FPS) specifically; for example, in observations of player behaviour in an FPS, Pinchbeck found that whilst players prioritised attention towards humanoid or moving objects, players seemed to care little for narrative during play, ignoring story-elements such as environmental storytelling [58]. However, further research identified that digital games with an emphasis on story enabled players to better recall and order their own experiences [59]. The influences of this research can be seen to be applied to Dear Esther; for example, after finding that players seem to prioritise humanoid characters and moving objects, Pinchbeck emphasises that Dear Esther presents a "sparse environment with no embedded agents" and notes the use of a humanoid figure (often interpreted as a ghost) to direct player attention [60].

Consequently, Pinchbeck specifically identifies ambiguity and abstraction as methods for "engaging the player's imagination" [61] and argues that "there's nothing more powerful than your own imagination, [it is] the most powerful tool you have at your disposal as a designer and as a writer". Indeed, Dear Esther "actively resisted" any direct interpretation, with an intentional lack of a final, 'correct' reading for the story, leading to an "enormous number of interpretations" posited by players.

Speaking in regards to the original version of Dear Esther, a Half-Life 2 [62] modification, the game relies "...purely on the player's engagement with and interpretation of a narrative delivered through semi-randomised audio fragments" [60], demonstrating the priority of interpretation as the player's primary form of engagement. Pinchbeck facilitates this interpretation during gameplay by being 'incredibly ambiguous and abstract'. For example, the story of Dear Esther involves no action; different characters are described, though none explicitly interact. Pinchbeck adopts this approach to avoid providing explicit information to the player and instead "suggests things that could have happened". For example, while players are only given six or seven pieces of information about the character Paul, who is also not visually represented, players' interpretations of the character are "phenomenally complicated". Hemingway's iceberg theory is again adopted, with Pinchbeck noting that this approach would "create tips of icebergs floating above the ocean of action".

A careful balance of abstraction and ambiguity is proposed to better engage players with story, suggesting that players "will automatically create a plot as they go through" and "if presented with something that looks and feels enough like a story, people are likely to interpret the action in a 'storied' way" [61]. For example, if at one point players 
are told 'Paul was drunk', then at another point it must also be implied that Paul may not have been drunk in order to maintain Paul's ambiguity. Similarly, Pinchbeck notes the use of abstraction through the mention of the biblical story of Lot's wife, intended to be analogous to various storylines and characters in Dear Esther; for example, Lot's wife is at times also implied to be Esther herself.

Pinchbeck emphasises that "if you increase ambiguity, if you increase abstraction, players will invest more heavily" as they are "not necessarily able to drop into that schematic way of doing things". This again suggests that the intended use of ambiguity and abstraction is to reduce players' reliance on established schema, again comparable to dishabituation [40].

Both Pinchbeck and Barlow present methods that focus on engaging the player's 'imagination', with various similarities. For example, both discuss the notion of inference and implication over explication, particularly in regard to Hemingway's iceberg theory. Similarly, the acknowledgement of a player's existing understanding of genres and stories and general narrative schema is considered in both Barlow's 'story literate' audiences and Pinchbeck's explicit discussion of schema. However, the psychological foundation of narrative interpretation can also be seen in digital games that aren't explicit in intentionally discouraging easy access to relevant schema.

\section{Empirical Study of Player Behaviour and Response in Gone Home}

While intentional methods of facilitating more effortful interpretation of narrative can be found in certain games, an analysis of play of a game with no documented intentional use of psychology (Gone Home [7]) demonstrates the relevance of the proposed structure of player psychology.

Fifteen participants each played fifteen minutes of Gone Home. Via a stimulated recall methodology [63], the participants viewed the recording of their gameplay and reported on their thoughts and feelings at particular moments, providing detailed descriptions of experience. These descriptions were explored via inductive thematic analysis in-line with the process outlined by Braun \& Clarke [64], identifying twenty themes from which connections to the psychological foundation proposed previously can be made. Some themes were significant due to their frequency of discussion across the entire participant group, whereas others were significant due to the frequency of discussion by a subset of participants.

The most prevalent theme identified was the formation of expectations. Participants frequently made predictions and voiced their expectations of the story ("maybe someone's dead, or some other tragedy has befallen the family") and of potential events that might occur within the game ("there might be, you know, a secret passage or a key beneath a rug"). Further emergent themes suggest how these expectations were informed, such as general prior knowledge ("...because it was like a caution or warning, a radioactivity sign, I knew that it was important, or, to go in there" or "obviously it says dark room, so I know a dark room is all about photo, photography"), or personal experiences (“...I always leave my keys under plant pots, I'll go look at the plant pots”, 
"sort of brought me back to my childhood" and recalling memories of "constantly having to make new friends"). Expectations were also informed by prior understanding of similar games ("I guess, just, um, player bias in that I've played video games before", "I have played games before, and uh, the door is locked, there's nowhere else out for me to explore, the answer is in this room..."). This ranged from specific titles to broader genres, with many participants attempting to categorise Gone Home themselves, typically into an existing genre ("the door right at the beginning, my first thoughts were, uh, it could be a horror game, based on the atmosphere", "I don't like horror games so, I was always a bit hesitant about like a jump scare"). The prominence of the discussion of prior expectations in players of Gone Home demonstrates how often players rely on their established schema to understand their experience and form further expectations.

These expectations were often abductive in their reasoning, with various potential outcomes considered - "Did she take it with her or is it somewhere else? Did she throw it away?", "So my, I guess, was she either died, or... she.... was kidnapped or possessed", "...so it could be either a boy or a girl".

Many of the discussions of expectations also coincide with situations that participants found uncertain ("Well something has happened and I don't know what it is") or strange and unfamiliar - such as in response to finding a school locker in a teen girl's bedroom (" to find that combination lock because like you know, it was a bit weird seeing a locker in her room ") or the television being left on in the living room ("who leaves a tv on when they leave the room, especially on like the static channel, like that's very strange to me"). This is similar to theories of curiosity and cognitive closure, and supports the idea that individuals are drawn to uncertain, novel stimuli.

Filtering of irrelevant information was also a common theme, with many participants noting information they had encountered that was unnecessary, with comments such as "...even though it's like such an irrelevant thing and irrelevant piece of information" or "there's little bits of things that I keep finding everywhere which primarily don't have any use other than just to show you what your family is like". This last participant suggests that whilst a piece of information has no immediate relevance to the story, it's general implication (what the family is like) is still considered and perhaps retained therefore, not all irrelevant information is completely disregarded and forgotten.

One participant in particular clearly demonstrates how they used their prior experiences with games more generally to inform how they approached Gone Home; "from previous experience from these sorts of games, my frustration in the past has been that I haven't looked at everything and I've missed something". This is another common theme that emerged - that participants were often systematic and thorough in their approach, often in the explicit pursuit of more narrative information with concern over missing vital details. This typically resulted in participants interacting with as much of the environment as possible, thoroughly examining their environments with great scrutiny; "trying to examine the environment with a magnifying glass, just trying to find that little bit that you missed", "I knew it was going to be one of those games where you had to look at everything", "we loot everything!".

This systematic and investigative approach also shows how participants often navigated the house of Gone Home more widely; "the stairs obviously looking all inviting, and there's a little light at the top, but no, I'm going to read everything first". Again, 
this reflects the careful systematic approach, but also shows how participants determined when each room should be searched; in this case, this participant felt that they were being encouraged to go upstairs, but wanted to complete their search of downstairs. This behaviour occurred frequently amongst eight of the participants; "now here you'll see me not take the obvious direction", "I didn't know whether I was exploring the house in the sort of correct way", "at least the developers want you to go in that direction". This differed between participants, but generally involved consideration of a 'correct' route through the house. While some voiced that they were trying to determine the developer/designer's intent, others only note that they were trying to go in the 'right direction'. Various cues are considered by some participants when deciding which way is the correct way; lighting, whether the path forward was visible (such as through an open door), and one participant noted the size of the staircase. However, Steve Gaynor, lead designer and writer of Gone Home, emphasised that while there are two possible routes at the start of the game, either up the stairs or through the left hallway, there is no preferred direction - to progress through the game, player's still need to find a key to unlock another portion of the house, but the specific route the player takes to find this key doesn't matter. This suggests that neither of these paths were 'signposted' or emphasised to players, which may indicate various environmental cues that players seek out when navigating an environment or that the participants retrospectively justified choices in navigation during stimulated recall. This has been discussed previous in regards to critical path design for story games (Higgins, 2019).

Common themes also suggest what kind of information participants retained from the story of Gone Home. Gone Home's story focuses on the missing family and involves uncovering pieces of information about their lives - therefore, as can be expected, participants frequently demonstrate their depth of understanding for Gone Home's characters. Much of this typically pertains to the relationships between characters and establishing how each character is connected. Earlier on in the game, this is focused on identifying the protagonist and player-character Katie ("I don't know who Katie is, I don't know if we're, I don't think we are Katie", "another reminder about um, Katie, which I assume is our character"). As participants acquire more information about the family, the more they are able to identify how they then relate to one-another - for example, Katie's sister Sam ("so, OK, I'm Katie, my sister's Sam", "so Sam, Katie... yeah Sam and Katie are sisters then"), their mother Janice ("I'm realising now that Janice is probably the mother", "I got the idea that she was the mother from a second marriage").

Themes found in the study of players of Gone Home reflect the current discussion of cognitive psychology and narrative interpretation. Constant recall and formation of expectations is comparable to discussion of schema theory, particularly in how participants often used their experiences of other games to inform their expectations. The recollections of narrative, particularly around characters, also reflects the discussion of situation models, and individuals' ability to retain a large amount of potentially relevant narrative information. However, these findings also suggest that individuals filter stimuli to determine how they might fit into current schema and situation models. The frequency at which participants were drawn to novel, confusing, uncertain stimuli also supports the propositions made in theories of curiosity, in addition to Berlyne's arousalincreasing factors (i.e. 'novelty, surprisingness, complexity, ambiguity, and 
puzzlingness'). Observations of participant behaviour also identified aversive behaviour in response to potentially excessive arousal, particularly when participants were scared, with some participants lifting the headphones from their ears to distance themselves from the game.

While the processing of narrative information may be similar across different media, observation shows how these processes mediate behaviour in digital games specifically. Further research into similar story-focused digital games would be beneficial to further testing the reliability of these cognitive psychological models and whether these behaviours and patterns of thought continue in other contexts.

\section{$7 \quad$ Conclusion and Future Work}

Adopting the perspective that the process of interpreting a narrative can be considered play, a psychological foundation of that process and how it may be pleasurable has been proposed and contextualized in contemporary practice in narrative design. Primary research of players in Gone Home reflects much of the proposed cognitive psychological model for narrative interpretation and arousal regulation and provides a potentially suitable basis for future research of psychology in the context of interpretive play.

A psychological foundation of interpretive play can be used to examine current approaches to narrative design in digital games, as well as inform new approaches. Whilst the primary research so far supports the proposed understanding of narrative interpretation and arousal regulation, further examination in varied game contexts is necessary to determine the consistency of these behaviours. Further to this, it would also be advantageous to measure physiological arousal using biometric feedback during play to examine how it may change during exposure to different narrative stimuli. For example, changes in arousal may help indicate the efficacy of specific design methods or could be used to determine general thresholds for unpleasant arousal.

Approaches to narrative design for digital games informed by cognitive psychology are also recommended to be tested in practice, primarily through development of commercial digital games. Similar psychological approaches to game design have been previously tested in this way, primarily in Amnesia: A Machine for Pigs [14, 16]. Potential approaches to narrative design specifically, adopting the proposed psychological basis, are thus being tested in the development of smaller commercial titles, the first of which being White Lake (with an early proof-of-concept demo currently available [65]), a story-focused game set in an abstract white void in which an environment constructs itself around the player as they explore and progress. Methods to facilitate arousal regulation through the discouraging of easy assimilation of schema and increased reliance on more effortful inference and interpretation shall be applied in the game's design and development. Following White Lake's release, player responses shall also analysed to determine the impact of the psychological approach on player experience. The ongoing aim of this work is to further investigate interpretive play in the context of digital games and continue to develop a cognitive psychological foundation of narrative interpretation, with a broader goal to contextualise the research and findings in commercial games development. 


\section{References}

1. Upton, B.: The aesthetic of play. MIT Press (2015)

2. Bozdog, M., Galloway, D.: Worlds at our fingertips: Reading (in) What Remains of Edith Finch. Games and Culture 1555412019844631 (2019)

3. Giant Sparrow: What Remains of Edith Finch. Annapurna Interactive, Los Angeles, CA (2017)

4. Boyd, B.: On the origin of stories. Harvard University Press (2009)

5. The Chinese Room: Dear Esther. The Chinese Room, Curve Digital, Brighton, United Kingdom and London, United Kingdom (2012)

6. Barlow, S.: Her Story. Self-published (2015)

7. The Fullbright Company, M.C.: Gone Home. The Fullbright Company and Majesco Entertainment, Portland, OR and Hazlet, NJ (2013)

8. Baddeley, A.: Working memory. Science 255, 556-559 (1992)

9. An, S.: Schema Theory in Reading. Theory \& Practice in Language Studies 3, (2013)

10.Mandler, J.M.: Stories, scripts, and scenes: Aspects of schema theory. Psychology Press (2014)

11.Bartlett, F.C.: Remembering: An experimental and social study. Cambridge: Cambridge University (1932)

12.Mercier, P., Kalampalikis, N.: Repeated reproduction: Back to Bartlett. A French replication of narrative and an extension to proverbs. Culture \& Psychology 1354067X19871197 (2019)

13.Rubínová, E., Blank, H., Koppel, J., Ost, J.: Schema and deviation effects in remembering repeated unfamiliar stories. British Journal of Psychology (2020)

14.Howell, P.: Disruptive Game Design: A Commercial Design and Development Methodology for Supporting Player Cognitive Engagement in Digital Games. Creative Technologies, vol. Doctor of Philosophy. University of Portsmouth (2015)

15.Howell, P.: A theoretical framework of ludic knowledge: a case study in disruption and cognitive engagement. In: 10th International Conference in the Philosophy of Computer Games, Valletta, Malta, October. (Year)

16.The Chinese Room: Amnesia: A Machine for Pigs. Frictional Games, Helsingborg, Sweden (2013)

17.Douglas, J.Y., Hargadon, A.: The pleasures of immersion and engagement: Schemas, scripts and the fifth business. Digital Creativity 12, 153-166 (2001)

18.Van Dijk, T.A., Kintsch, W.: Strategies of discourse comprehension. (1983)

19.Zwaan, R.A., Radvansky, G.A.: Situation models in language comprehension and memory. Psychological bulletin 123, 162 (1998)

20.Zwaan, R.A., Langston, M.C., Graesser, A.C.: The construction of situation models in narrative comprehension: An event-indexing model. Psychological science 6, 292-297 (1995)

21.Zacks, J.M., Speer, N.K., Swallow, K.M., Braver, T.S., Reynolds, J.R.: Event perception: a mind-brain perspective. Psychological bulletin 133, 273 (2007)

22.Zacks, J.M., Swallow, K.M.: Event segmentation. Current directions in psychological science $16,80-84$ (2007)

23.Newtson, D., Engquist, G.: The perceptual organization of ongoing behavior. Journal of Experimental Social Psychology 12, 436-450 (1976) 
24.Quantic Dream: Detroit: Become Human. Sony Interactive Entertainment, San Mateo, CA (2018)

25.Oatley, K.: A taxonomy of the emotions of literary response and a theory of identification in fictional narrative. Poetics 23, 53-74 (1994)

26.Csikszentmihalyi, M., Csikzentmihaly, M.: Flow: The psychology of optimal experience. Harper \& Row New York (1990)

27.Oliver, M.B., Bartsch, A.: Appreciation of Entertainment. Journal of Media Psychology 23, 29-33 (2011)

28.Cohen, A.R., Stotland, E., Wolfe, D.M.: An experimental investigation of need for cognition. The Journal of Abnormal and Social Psychology 51, 291 (1955)

29.Cacioppo, J.T., Petty, R.E.: The need for cognition. Journal of personality and social psychology 42, 116 (1982)

30.Cacioppo, J.T., Petty, R.E., Feng Kao, C.: The efficient assessment of need for cognition. Journal of personality assessment 48, 306-307 (1984)

31.Litman, J.: Curiosity and the pleasures of learning: Wanting and liking new information. Cognition \& emotion 19, 793-814 (2005)

32.Edelman, S.: Curiosity and exploration. Retrieved May 11, 20 (1997)

33.Litman, J.A., Jimerson, T.L.: The measurement of curiosity as a feeling of deprivation. Journal of personality assessment $82,147-157$ (2004)

34.Litman, J.A.: Interest and deprivation factors of epistemic curiosity. Personality and individual differences 44, 1585-1595 (2008)

35.Costikyan, G.: Uncertainty in games. Mit Press (2013)

36.To, A., Ali, S., Kaufman, G.F., Hammer, J.: Integrating Curiosity and Uncertainty in Game Design. In: Digra/fdg. (Year)

37.Kruglanski, A.W., Webster, D.M.: Motivated closing of the mind:" Seizing" and" freezing.". Psychological review 103, 263 (1996)

38.Webster, D.M., Kruglanski, A.W.: Individual differences in need for cognitive closure. Journal of personality and social psychology 67, 1049 (1994)

39.Hiel, A.v., Mervielde, I.: The need for closure and the spontaneous use of complex and simple cognitive structures. The Journal of social psychology 143, 559-568 (2003)

40.Berlyne, D.E.: Aesthetics and Psychobiology. Appleton-Century-Crofts, Meredith Corporation, New York (1971)

41.Gaver, W.W., Mandler, G.: Play it again, Sam: On liking music. Cognition and Emotion 1, 259-282 (1987)

42.Reisenzein, R., Horstmann, G., Schützwohl, A.: The cognitive-evolutionary model of surprise: A review of the evidence. Topics in cognitive science 11, 50-74 (2019)

43.Nell, V.: Lost in a Book: The Psychology of Reading for Pleasure. Yale University Press, New Haven, Connecticut (1988)

44.Matsubara, M., Augereau, O., Sanches, C.L., Kise, K.: Emotional arousal estimation while reading comics based on physiological signal analysis. In: Proceedings of the 1st International Workshop on coMics ANalysis, Processing and Understanding, pp. 1-4. (Year)

45.Gregersen, A., Langkjær, B., Heiselberg, L., Wieland, J.L.: Following the viewers: Investigating television drama engagement through skin conductance measurements. Poetics 64 , $1-13(2017)$ 
46.Bhattacharjee, T., Datta, S., Das, D., Choudhury, A.D., Pal, A., Ghosh, P.K.: A Heart Rate Driven Kalman Filter for Continuous Arousal Trend Monitoring. In: 2018 40th Annual International Conference of the IEEE Engineering in Medicine and Biology Society (EMBC), pp. 3572-3577. IEEE, (Year)

47.Hirokawa, E.: Effects of music listening and relaxation instructions on arousal changes and the working memory task in older adults. Journal of Music Therapy 41, 107-127 (2004)

48.Piaget, J.: Piaget's theory. Piaget and his school, pp. 11-23. Springer (1976)

49.Brewer, W.F.: The nature of narrative suspense and the problem of rereading. Suspense: Conceptualizations, theoretical analyses, and empirical explorations 107-127 (1996)

50.Brewer, W.F., Lichtenstein, E.H.: Stories are to entertain: A structural-affect theory of stories. Center for the Study of Reading Technical Report; no. 265 (1982)

51.Truffaut, F., Hitchcock, A., Scott, H.G.: Hitchcock. Simon and Schuster (1984)

52.Smith, P.: Hemingway's Early Manuscripts: The Theory and Practice of Omission. Journal of Modern Literature 10, 268-288 (1983)

53.Barlow, S.: Telling Lies. Annapurna Interactive, California, US (2019)

54.Game Developers Conference, https://www.gdcvault.com/play/1023430/Making-Her-StoryTelling-a

55.Blendo Games: Thirty Flights of Loving. Idle Thumbs, San Francisco, CA (2012)

56.Variable State: Virginia. 505 Games, Milan, Italy (2016)

57.Pinchbeck, D., Stevens, B.: Presence, narrative and schemata. In: Proceedings of Presence 2005: The 8th International Workshop on Presence, pp. 221-226. (Year)

58.Pinchbeck, D., Stevens, B., Van Laar, S., Hand, S., Newman, K.: Narrative, agency and observational behaviour in a first person shooter environment. In: Proceedings of Narrative AI and Games Symposium: Society for the Study of Artificial Intelligence and the Simulation of Behaviour (AISOB'06), pp. 53-61. SSAISB, (Year)

59.Pinchbeck, D.: Story and recall in first-person shooters. International Journal of Computer Games Technology 2008, 6 (2008)

60.Pinchbeck, D.: Dear Esther: an interactive ghost story built using the source engine. In: Ulrike Spierling, N.S. (ed.) Joint International Conference on Interactive Digital Storytelling, vol. 5334, pp. 51-54. Springer-Verlag, Erfurt, Germany (2008)

61.Game Developers Conference,

62.Valve Corporation: Half-Life 2. Self-published, Bellevue, WA (2004)

63.Pitkänen, J.: Studying thoughts: Stimulated recall as a game research method. Game research methods, pp. 117-132 (2015)

64.Braun, V., Clarke, V.: Using thematic analysis in psychology. Qualitative research in psychology 3, 77-101 (2006)

65.Higgins, M.: White Lake. Self-published (2015) 